\title{
Pemberdayaan Ibu Rumah Tangga dalam Meningkatkan Produktivitas Masa Pandemi Covid-19 di Desa Tigawasa
}

\author{
Putu Mita Sintya Dewi ${ }^{1 *}$,Ni Ketut Elly Sutrisni ${ }^{2}$ \\ Program Studi Manajemen, Fakultas Ekonomi dan Bisnis, \\ Universitas Pendidikan Nasional \\ Jl.Bedugul No.39,Sidakarya, Kec. Denpasar Sel., Kota \\ Denpasar, Bali 80224 \\ *Penulis Koresponden : mitacintya84@gmail.com
}

\begin{abstract}
ABSTRAK
Desa Tigawasa merupakan salah satu Desa Purba ( Bali Aga ) yang berada di Kecamatan Banjar ,Kabupaten Buleleng, Provinsi Bali, Indonesia. Secara geografis keberadaan Desa ini memiliki luas wilayah 1.690 Ha yang sebagian besar merupakan wilayah perbukitan ,melingkupi daerah perbukitan yang dimana menyebabkan letak Desa ini cukup terpencil, namun akses jalan menuju desa tersebut sudah menggunakan jalan aspal dengan konstuksi jalan yang lumayan harus berhati-hati jika melewati Desa tersebut karena jalan yang menanjak dan curam. Selain itu desa ini juga memiliki potensi dalam kesenian yang dikembangkan oleh masyarakat seperti Sekaa Shanti dan Sekaa Joged yang dijadikan aset oleh masyarakat setempat.Berada di daerah perbukitan maka cuaca di Desa tersebut lumayan lembab dan curah hujan yang lumayan tinggi serta sinar matahari yang bagus menyebabkan Desa ini memiliki sumber daya alam yang melimpah antara lain : cengkeh,kopi dan masih banyak hasil bumi lainnya. Dari letak Desa tersebut menyebabkan sebagian besar warga Desa bermata pencaharian sebagai petani,selain itu tumbuh juga beberapa usaha-usaha lainnya seperti warung,peternakan dan beberapa home industri. Potensi sumber daya alam yang dihasilkan Desa tersebut dapat dimanfaatkan untuk meningkatkan perekonomian warga sekitar dengan penggunaan cara yang tepat.
\end{abstract}

Kata kunci : Produktivitas, pengembangan, pemanfaatan, pandemi

\section{ABSTRACT}

Tigawasa Village is one of the Ancient Villages (Bali Aga) located in Banjar District, Buleleng Regency, Bali Province, Indonesia. Geographically the existence of this village has an area of 1,690 ha which is mostly a hilly area, covering the hilly area that causes the location of this village is quite remote, but the road access to the village already uses asphalt roads with a fairly careful road construction should be careful if passing through the village because of the uphill and steep roads. In addition, this village also has potential in the arts developed by the community such as Sekaa Shanti and Sekaa Joged which are used as assets by the local community. Being in a hilly area, the weather in the village is quite humid and the rainfall is quite high and good sunlight causes this village to have 
Putu Mita Sintya Dewi, dkk.

abundant natural resources, among others: cloves, coffee and many other produce. From the location of the village causes most of the villagers have a livelihood as farmers, in addition to growing also some other businesses such as stalls, farms and some home industries. The potential of natural resources produced by the village can be used to improve the economy of the surrounding residents by using the right way.

\section{Keywords: Productivity, development, utilization, pandemic}

\section{PENDAHULUAN}

Pelaksanaan kegiatan KKN yang dilaksanakan oleh Lembaga Perguruan Tinggi merupakan salah satu kegiatan pemberdayaan sebagai bentuk pengabdian kepada masyarakat guna menunjang pembangunan disegala aspek kehidupan. KKN juga merupakan salah satu bentuk pembelajaran mahasiswa dilingkup masyarakat, dunia usaha dan instansi pemerintah/swasta sebagai bentuk aplikasi dan pembaruan kerangka teori yang telah diperoleh. Semua itu bertujuan untuk membekali mahasiswa agar dapat membaur dan menerapkan ilmu pengetahuan yang diperolehnya selama berada di bangku kuliah sehingga mahasiswa akan memperoleh bekal yang cukup sebelum terjun dalam kehidupan nyata ditengah masyarakat. Ekstensi mahasiswa adalah sebagai motivator,penggerakn peberi ide atau memberikan bantuan pemikiran pemecahan dalam suatu permasalahan yang dihadapi oleh masyarakat.

Namun seperti yang kita tahu, dalam keadaan pandemi seperti sekarang ini merupakan suatu masalah bagi kita semua bukan hanya pada sektor kesehatan namun disemua bidang kehidupan. Segala sesuatu berdampak karena adanya Pandemi Covid19 ini,yang dimana artinya segala gerakan yang kita lakukan menjadi terbatas demi keamanan bersama. Lingkup kerja yang sudah kita rencanakan juga harus dialihkan ke berbagai macam cara dan beberapa ada yang harus dibatalkan. Sebagai bentuk apresiasi Universitas terhadap apapun yang sudah terjadi maka dari itu kebijakan untuk melaksanakan KKN akan tetap berlangsung dengan cara online agar meminimalizir ruang gerak yang memungkinkan terjadinya masalah, maka Universitas memberikan kebijakan untuk mahasiswa tetap melaksanakan $\mathrm{KKN}$ dengan cara online tanpa mengurangi makna dari pelaksanaan kegiatan tersebut.

Maka dari itu sebagai bentuk pengabdian saya terhadap masyarakat serta untuk membantu meningkatkan perekonomian di desa yang memiliki potensi sumber daya alam melimpah di masa Pandemi Covid-19, saya mengajak para ibu rumah tangga agar menjadi lebih produktiv guna membantu meningkatkan perekonomian Desa dengan cara menghasilakan sesuatu yang bisa dijual dengan memanfaatkan sumber daya alam yang ada disekitar Desa Tigawasa. Selanjutnya adalah bagaimana memberikan beberapa pengetahuan untuk mempromosikan produk yang dihasilkan untuk selanjutnya apat dijadikan contoh dan motivasi untuk menciptakan produk-produk lain dengan memanfaatkan sumber daya alam yang ada disekitar agar memiliki nilai jual untuk mengembangkan perekonomian Desa.

\section{METODE PELAKSANAAN KEGIATAN}

Metode yang digunakan dalam kegiatan ini adalah berupa metode penelitian survei yang dijabarkan dalam beberapa kegiatan, yang pertama yaitu : observasi yang 
merupakan aktivitas terhadap suatu proses atau objek dengan maksud merasakan dan kemudian memahami pengetahuan melalui fenomena Desa tersebut yang berdasarkan pada beberapa landasan yaitu pengetahuan dan gagasan yang sudah diketahui sebelumnya. Lalu ada tahapan persiapan, dalam tahap ini ada sesi wawancara yang dilakukan beberapa kali terhadap beberapa sumber terkait guna menggali lagi informasi mengenai daerah yang akan menjadi pelaksanaan kegiatan.

Adapun langkah - langkah tersebut sebagai berikut :

1. Observasi

Observasi adalah aktivitas terhadap suatu proses dengan maksud merasakan dan kemudian memahami pengetahuan dari sebuah fenomena berdasarkan pengetahuan dan gagasan yang sudah diketahui sebelumnya, untuk mendapatkan informasi untuk selanjutnya diolah menjadi suatu penelitian. Pada tahap ini, penulis melaksanakan observasi mulai dari tanggal 26 Januari 2021 melalui media sosial dan beberapa sumber terkait Desa Tigawasa, dengan tujuan mengetahui permasalahan dan potensi apa yang terdapat di dalam Desa tersebut. Setelah mengetahui permasalahan dan potensi dari desa tersebut barulah dapat disimpulkan masyarakat yang menjadi sasaran untuk dapat diajak bersama-sama dalam hal memecahkan masalah dan mengembangkan potensi yang ada di Desa tersebut.

2. Persiapan kegiatan

Pada tahap ini penulisan menyusun hal-hal penting terkait pelaksanaan kegiatan yang harus segera dilakukan dengan tujuan mengefektifkan waktu dan pekerjaan. Dengan itu ada beberapa hal yang penulis siapkan di tahap ini :

- Penulis mempersiapkan penyusunan jadwal pelaksanaan kegiatan

- Menentukan lahan mana yang mudah di jangkau untuk mendapatkan bambu

- Serta merencanakan rapat terhadap beberapa sumber terkait kegiatan

- Tidak lupa pula untuk memberikan informasi terkait dengan protokol kesehatan yang wajib diterapkan.

3. Pelaksanaa Kegiatan

Dalam tahap ini penulis sudah mempersiapkan kebutuhan yang diperlukan dalam melaksanakan kegiatan seperti :

- Persiapan Bahan

Persiapan bahan sudah dipersiapkan seminggu sebelum pelaksanaan kegiatan berangsung karena pada tahap ini bambu yang dapat digunakan untuk menjadi siap dalam pembuatan sokasi memerlukan beberapa tahapan ,yaitu :

A. Pengambilan bambu di lahan

B. Pemotongan bambu sesuai dengan ukuran sokasi yang diperlukan, dengan ukuran diameter $18 \mathrm{~cm}, 20 \mathrm{~cm}, 25 \mathrm{~cm}$, dan $30 \mathrm{~cm}$ 
Putu Mita Sintya Dewi, dkk.

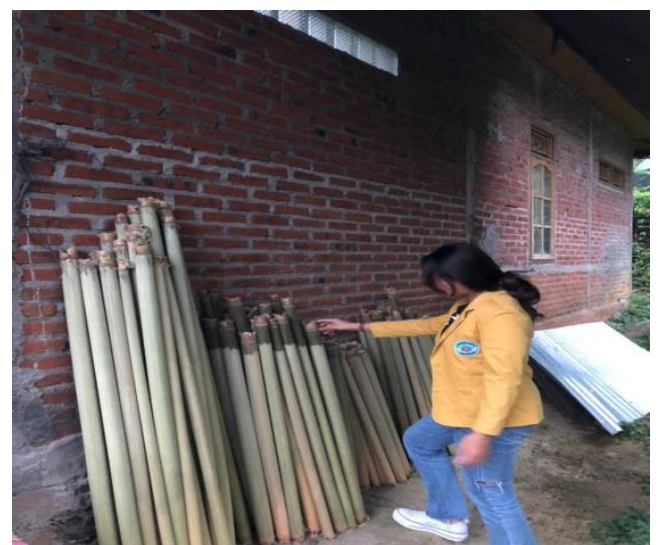

Gambar I. Sampel beberapa bambu yang sudah dipotong sesuai ukuran.

\section{Pengecatan pada bambu}

Pada proses ini bambu memerlukan sinar matahari yang cukup agar pewarna dapat mengering dengan baik dan cepat

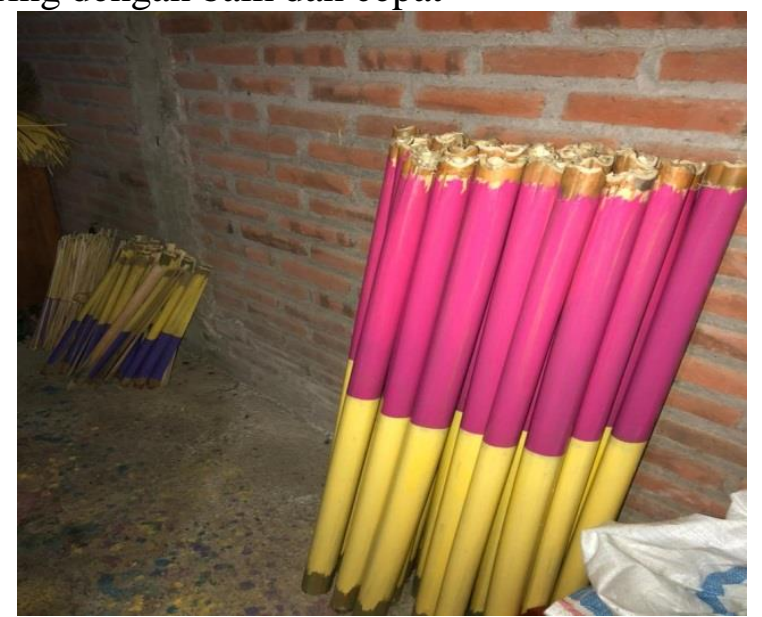

Gambar II. Bambu yang sudah melewati proses pewarnaan

D. Selanjutnya pada tahap yang dinamakan nyitsit,di tahap ini yang diambil adalah bagian kulit dari bambu untuk siap dianyam.

E. Proses penganyaman menjadi tikar lalu dikumpulkan agar nanti lebih mudah untuk dibentuk menjadi sokasi.

F. Proses ini dinamakan pembentukan dan finishing, disinilah hal terpenting kedua karena pembentukan akan dilihat dari bagaimana proses di tahap menganyam dilakukan. 
BAKTIMAS

Jurnal Pengabdian pada Masyarakat
Vol. 3, No. 1,

Maret 2021
eISSN 2685-113x

pISSN 2685-0303

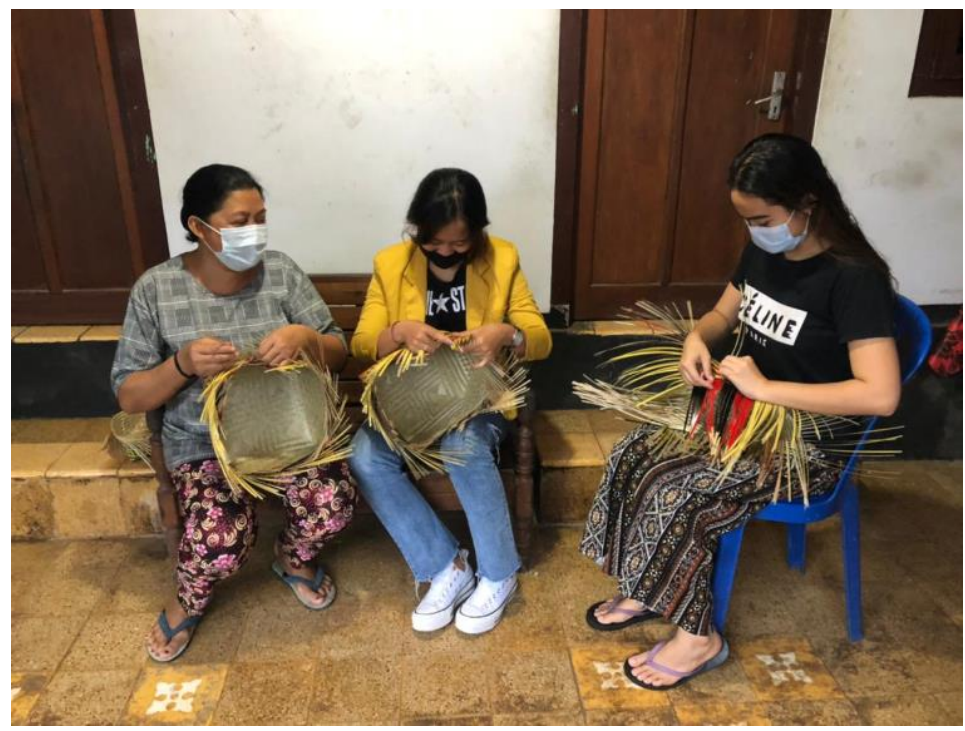

Gambar III. Proses finishing

G. Lalu selanjutnya dilakukan pengecekan berkala guna mendapatkan produk yang berkualitas.

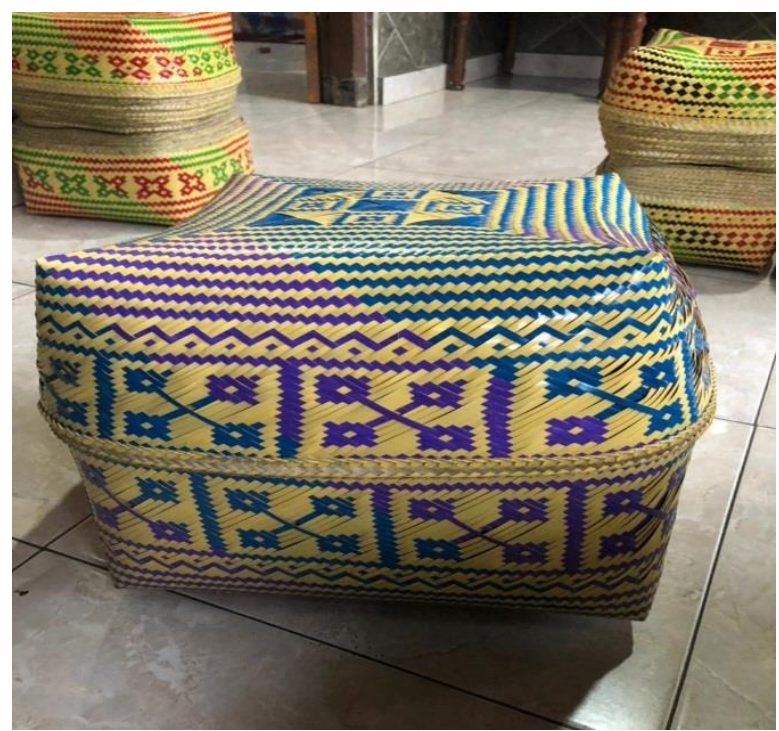

Gambar IV . Proses pengecekan

4. Evaluasi hasil produk

Pada tahap ini dilakukan beberapa pembenahan dan penilaian terhadap keberhasilan membuat anyaman dari bambu yang berbentuk sokasi dan pengevaluasian terhadap kinerja ibu rumah tangga di Desa Tigawasa guna meningkatkan perekonomian. Berikut adalah ulasan mengenai kendala dalam pelaksanaan kegiatan :

\section{Tahap observasi}

Pada tahap ini penulis kesulitan dalam menentukan dan memilah beberapa informasi di media sosial mengenai kendala dan potensi Desa tersebut. Selain itu kendala saat observasi yaitu cuaca di musim hujan saat ini,karena curah hujan yang lumayan tinggi dan geografis Desa tersebut yang tidak mudah dijangkau menyebabkan 
Putu Mita Sintya Dewi, dkk.

beberapa hal harus ditunda terlebih mengutamakan kepentingan bersama. Serta penerapan kegiatan dengan protokol kesehatan juga menyebabkan adaanya perbedaan jika dibandingkan dengan sebelum adanya pandemi covid-19.

\section{Tahap Persiapan}

Di tahap ini yang menjadi kendala karena terjadi di awal tahap observasi dengan curah hujan yang lumayan tinggi menyebabkan persiapan yang penulisan dan beberapa rekannya mengalami kesulitan untuk berinteraksi secara langsung ditambah lagi dengan adanya covid-19 ini, dimana pengaturan rencana kurang adanya sosialisasi face to face dan kebanyakan dilakukan secara daring dengan sinyal yang tidak memungkinkan pula,namun perenanaan tetap ada walaupun belum maksimal.

\section{Tahap Pelaksanaan}

Pada tahap ini penulis kesulitan untuk menentukan pemilihan bahan karena lagi lagi curah hujan yanng tinggi menyebabkan lahan bambu menjadi sedikit lembab dan akses menuju ke lahan yang lumayan memakan energi, serta kendala pada saat penjemuran kulit bambu karena memerlukan matahari untuk mengeringkan cat namun curah hujan tinggi menyebabkan proses pembuatan bahan menjadi lebih lama dari biasanya.

\section{HASIL DAN PEMBAHASAN}

Adapun hasil yang diperoleh dalam kegiatan pengabdian masyarakat dalam program Kuliah Kerja Nyata periode 1 Februari sampai dengan 17 Maret 2021 di Desa Tigawasa,Kecamatan Banjar ,Kabupaten Buleleng berupa produk sokasi.

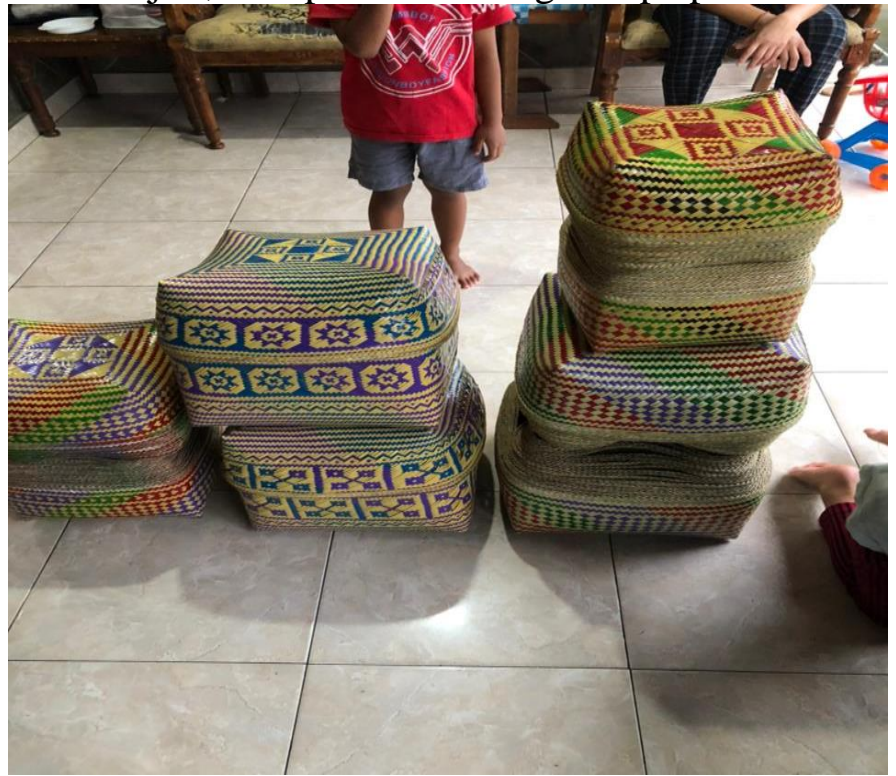

Gambar V. Produk sokasi(tempat banten yang terbuat dari kulit bambu) dengan berbagai ukuran dan motif

Produk yang dibuat bertujuan untuk meningkatkan produktivitas terutama ibu rumah tangga ,namun masyarakat yang bukan ibu rumah tangga juga dapat menekuni hal ini, selain untuk meningkatkan produktivitas ,tujuan selanjutnya diharapkan dengan 
pemanfaatan sumber daya alam dengan baik mampu meningkatkan nilai ekonomi warga sekitar.

Dengan ini dapat dijabarkan melalui tabel berikut :

Tabel I . Perbandingan rata-rata penghasilan warga dalam sebulan sebelum dan sesudah penjualan sokasi di masa pandemi.

\begin{tabular}{|c|c|}
\hline \multicolumn{2}{|c|}{ Penghasilan Rata-Rata Warga Dalam Sebulan } \\
\hline Sebelum & Sesudah \\
\hline Rp.4.000.000,- & Rp. 4.800.000,- \\
\hline
\end{tabular}

Berdasarkan tabel diatas ,dapat dilihat bahwa terjadi peningkatan jumlah penghasilan. Melalui informasi dari beberapa sumber yang menjadi mitra penulis, harga jual sokasi ini berkisar Rp. 25.000., sampai dengan Rp. 170.000., yang tergantung pada ukuran, kualitas dan motif dari produk tersebut.

Dengan pemanfaatan sumber daya alam diharapkan peningkatan ekonomi ini dapat berlangsung dengan signifikan dan terus meningkat.

\section{Simpulan}

\section{PENUTUP}

Kegiatan pengabdian ini dilakukan guna untuk mengetahui lebih dalam mengenai kondisi di suatu tepat dengan melihat peluang yang memungkinkan di daerah tertentu dan untuk mahasiswa memiliki tantangan untuk bisa mengolah peluang tersebut menjadi sesuatu yang bermanfaat serta mencari solusi terkait permasalahan yang ada. Maka dengan begitu akan berdampak baik bukan hanya pada individu itu sendiri tapi dapat bermanfaat untuk bnyak orang dengan harapan kegiatan baik tersebut terlaksana dalam kurun waktu yang terus-menerus. Pada fokus di Desa Tigawasa, kegiatan ini diharapkan mampu meningkatkan produktivitas para ibu rumah tangga yang tidak memiliki pekerjan tetap untuk dapat mengembangkan potensi diri dan menghabiskan waktu luang dengan hanya memanfaatkan potensi sumber daya alam yang ada disekitar. Dengan begitu kegiatan tersebut dapat berupa output yang memiliki nilai sehingga dapat dipasarkan,dengan harapan dapat meningkatkan perekonomian di dalam keluarga ,lalu dilingkungan sekitar.

\section{DAFTAR PUSTAKA}

bulelengkab.go.id > detail > artikelDesa Tua Tigawasa - Kabupaten Buleleng tigawasa-buleleng.desa.id > artikelSejarah Desa - Website Desa Tigawasa eprints.uad.ac.id > ...PDFHasil webBAB I PENDAHULUAN A. Latar Belakang Pelaksanaan KKN Kuliah ...

eprints.uny.ac.id > ...PDF1 BAB I PENDAHULUAN A. Latar Belakang ... - Lumbung Pustaka UNY 